\title{
Geociênciajass
}

\section{pH e umidade dos resíduos finos de beneficiamento de rochas ornamentais}

\section{The $\mathrm{pH}$ and humidity of fine wastes from processing dimension stones}

\section{Mirna Aparecida Neves \\ Universidade Federal do Espírito Santo, Professora Adjunta do Curso de Geologia. mirna@cca.ufes.br \\ Carolina Peterle de Nadai \\ Universidade Federal do Espírito Santo, \\ Graduando no Curso de Geologia. \\ carolinadenadai@hotmail.com}

\section{Arthur Bazoni da Fonseca \\ Universidade Federal do Espírito Santo, Graduando no Curso de Geologia. \\ arthurbazoni@yahoo.com.br}

\section{Ana Candida de Almeida Prado Universidade Federal do Ceará, Professora Adjunta do Curso de Engenharia de Materiais. \\ acaprado@cariri.ufc.br}

\section{Juliana Di Giorgio Giannotti}

Universidade Federal do Espírito Santo, Professora Adjunta do Curso de Geologia. jggiannotti@cca.ufes.br

\section{Valério Raymundo}

Sindirochas, Consultor em Licenciamento Ambiental e Gestão de Resíduos.

valerio30@gmail.com

\section{Resumo}

Apresenta-se um estudo do comportamento do $\mathrm{pH}$ e da taxa de umidade dos resíduos finos de beneficiamento de rochas ornamentais. Amostras foram coletadas durante a serragem de blocos e polimento das chapas e,ainda, após passarem pelo filtro-prensa. Foram coletadas de depósitos de diferentes idades, incluindo um depósito temporário de 3 meses, um depósito de 5 anos e outro de 20 anos. $\mathrm{O}$ pH e a taxa de umidade foram medidos de acordo com as NBR 10.004/2004 e 10.006/2004. No que se refere ao $\mathrm{pH}$, os resíduos não se enquadraram na classe dos perigosos, em nenhum dos casos estudados. Esse parâmetro decai com o tempo, mesmo em condições inadequadas de armazenamento. O estudo mostrou que o uso do filtro-prensa diminui o $\mathrm{pH}$ e a umidade do resíduo conforme as exigências normativas e que o mesmo resultado pode ser obtido em leitos de secagem construídos corretamente. Problemas de umidade foram observados no depósito antigo, onde os valores aumentam com a profundidade, chegando aos níveis do resíduo recém-gerado mesmo após 20 anos de armazenamento. Esses resíduos estão situados em planície aluvionar e próximos a um canal de drenagem.

Palavras-chave: $\mathrm{pH}$, umidade, gestão de resíduos, rochas ornamentais.

\begin{abstract}
The aim of this work was to analyze $\mathrm{pH}$ and humidity variations of fine wastes from processing dimension stones. Samples were collected during block cutting; plate polishing; after filter press and at deposits of different ages, including a temporary deposit 3 months old, a deposit of wastes 5 years old and another 20 years old. The $\mathrm{pH}$ and humidity were measured according to NBR 10.004/2004 and NBR 10.006/2004. Regarding pH values, wastes are not classified as dangerous in any case. Such parameter decays with time, even at inadequate storing conditions. This research showed that the use of a filter press decreases the $\mathrm{pH}$ and humidity of wastes according to regulatory requirements and the same results can be reached using correctly built pond drying. Humidity problems were found in the ancient deposit, where values increased at depth, reaching levels similar to newly generated wastes even after 20 year of storing. These wastes are located at alluvial plain, near a drainage channel.
\end{abstract}

Keywords: $p H$, humidity, waste management, dimension stones. 


\section{Introdução}

A indústria de rochas ornamentais gera grande quantidade de resíduos, destacando-se o material de granulação fina, denominado "lama abrasiva", produzido durante o processo de beneficiamento. Esse processo envolve a serragem, para transformar blocos em chapas, e o polimento e o corte, para transformar chapas em ladrilhos e outros produtos. A cada

$\mathrm{O} \mathrm{pH}$ tem sido apontado como uma das principais características negativas dos resíduos finos de rochas ornamentais, isto por representar riscos ao meio ambiente. De fato, segundo a norma de classificação de resíduos sólidos NBR-10004 da Associação Brasileira de Normas Técnicas - ABNT (ABNT, 2004a), resíduos que apresentarem $\mathrm{pH}$ menor do que 2,0 ou maior do que 12,5 devem ser classificados como perigosos, devido à sua corrosividade. Freitas et al. (2009) mediram pH entre 12 e 13, no resíduo coletado, durante o processo de serragem, mas afirmaram que a tendência é que haja decaimento desses valores, ao longo do tempo.

Porém não há conhecimento prévio sobre a variação desse parâmetro, ao longo do processo de beneficiamento, tampouco seu comportamento em depósitos jovens e antigos. Cabe citar que, até o final dos anos 90, a problemática

\section{Materiais e métodos}

Os locais de coleta foram selecionados tendo-se como meta analisar o $\mathrm{pH}$ e o teor de umidade dos resíduos, desde sua geração, no parque de beneficiamento, até seu armazenamento em depósitos tonelada de rocha transformada, estimase a produção de $0,10 \mathrm{~m}^{3}$ de efluente, dos quais $80 \%$ são gerados na operação de serragem (Pereira, 2006). Calmon e Silva (2006) calculam a produção de $60 \mathrm{mil}$ toneladas por mês de resíduos de rochas ornamentais só no Estado do Espírito Santo, onde é processada a maior parte dos granitos e mármores brasileiros.

$$
\begin{aligned}
& \mathrm{CaO}+\mathrm{H}_{2} \mathrm{O} \rightarrow \mathrm{Ca}(\mathrm{OH})_{2} \\
& \mathrm{Ca}(\mathrm{OH})_{2} \Leftrightarrow \mathrm{Ca}^{+2}+2 \mathrm{OH}^{-1}
\end{aligned}
$$

da geração desses resíduos foi, praticamente, ignorada e grandes quantidades foram descartadas de forma inadequada, sem impermeabilização do solo, próximos a canais de drenagem e do lençol freático. Com o crescimento da indústria e a produção cada vez maior de rochas ornamentais destinadas à exportação, maior atenção passou a ser dirigida para essa questão, em busca de soluções e de minimização de impactos pelo setor.

O Instituto Estadual do Meio Ambiente e Recursos Hídricos do Espírito Santo (IEMA) publicou a Instrução Normativa $\mathrm{n}^{\circ} 12$, em 03 de dezembro de 2007, estabelecendo critérios e procedimentos de localização, implantação e monitoramento de aterros, para a disposição permanente dos resíduos de rochas ornamentais (IEMA, 2007). Uma das exigências é que o teor de umidade do resíduo seja reduzido a, pelo menos, $30 \%$, antes de o resíduo ser encaminhado para
O resíduo gerado, durante a serragem dos blocos, feita em tear convencional, é formado, basicamente, pelo pó da rocha, cal, granalha, lâmina de aço e água. A cal utilizada no processo confere ao resíduo $\mathrm{pH}$ elevado, como resultado da dissolução da cal hidratada, conforme a reação: os aterros finais. A redução da umidade pode ser obtida a partir da utilização do filtro-prensa ou por meio de secagem ao ar livre em leitos de secagem impermeabilizados e com sistema de drenagem. Muita discussão existe no setor com relação à maior eficiência do filtro-prensa em relação ao leito de secagem.

Outra questão importante é quanto aos passivos ambientais representados pelos depósitos mais antigos, muitas vezes instalados sem impermeabilização do solo e em locais inadequados, colocando os efluentes em contato com as águas de rios e aquíferos.

Com base na problemática anteriormente exposta, concebeu-se a ideia desse trabalho, cujo objetivo foi estudar o comportamento do $\mathrm{pH}$ e do teor de umidade dos resíduos em diversas fases, desde sua geração, ainda no parque de beneficiamento, até a disposição em leitos de secagem e depósitos de diferentes idades.

de diferentes idades. A Tabela 1 relaciona o local de coleta das amostras e a codificação que será utilizada nesse trabalho.

O resíduo da saída da boca do tear (TE) corresponde àquele gerado na eta-

pa de desdobramento, ou seja, durante a serragem dos blocos em placas semiacabadas ou chapas brutas (Figura 1A). O corte é feito em teares de fios diamantados ou de lâminas de aço. Os teares de

\begin{tabular}{c|c}
\hline Local de coleta das amostras & Sigla \\
\hline Saída da boca do tear & TE \\
\hline Saída da politriz & PO \\
\hline Saída do filtro prensa & $\mathrm{FP}$ \\
\hline Depósito novo (1 a 3 meses de idade) a 1 metro de profundidade & DN-1 \\
\hline Depósito novo (1 a 3 meses de idade) a 2 metros de profundidade & DN-2 \\
\hline Depósito de idade intermediária (4 a 5 anos de idade) a 1 metro de profundidade & DI-1 \\
\hline Depósito de idade intermediária (4 a 5 anos de idade) a 2 metros de profundidade & DI-2 \\
\hline Depósito antigo (18 a 20 anos de idade) a 1 metro de profundidade & DA-1 \\
\hline Depósito antigo (18 a 20 anos de idade) a 2 metros de profundidade & DA-2 \\
\hline Depósito antigo (18 a 20 anos de idade) a 3 metros de profundidade & DA-3 \\
\hline
\end{tabular}

\section{Tabela 1}

Locais de coleta e siglas adotadas para as amostras de resíduo analisadas. 
lâminas de aço são os mais comuns; neles circula uma polpa composta por granalha de aço, cal e água. Parte dessa polpa é descartada após o desgaste, com a redução acentuada do tamanho dos grãos. Gera-se, assim, um resíduo (ou lama) composto por pó de rocha, pó de lâminas de aço, granalha, cal e água. Os resíduos oriundos do tear diamantado são compostos apenas por pó de rocha e água, mas eles não foram incluídos nesse estudo, pois, embora exista uma tendência de substituição dos teares convencionais por tear diamantado, estes ainda são minoria no Estado do Espírito Santo.

As chapas brutas são encaminhadas para o polimento, gerando outro tipo de resíduo (PO). O resíduo gerado é composto por água, pó de rocha, abrasivos e, em alguns casos, por resinas poliméricas, que são usadas para preencher microfissuras e poros da rocha, conferindo, assim, maior brilho ao produto final. $\mathrm{O}$ efluente dessa etapa é encaminhado para tanques de decantação (Figura 1B), onde o líquido sobrenadante retorna para o sistema e o material particulado sofre sedimentação. Periodicamente, os tanques são esvaziados para limpeza e, geralmen- te, os resíduos do polimento são misturados aos do corte e encaminhados para o leito de secagem ou para o filtro-prensa.

Quando o filtro-prensa é utilizado, gera-se o outro tipo de resíduo, aqui estudado (FP). O filtro-prensa é um equipamento que separa grande parte da água presente na lama abrasiva (Figura 1C), com o objetivo de se reduzir a umidade do material antes da armazenagem. A água retirada pode ser reaproveitada no sistema e o resíduo pode ser encaminhado diretamente aos aterros finais sem passar pelo leito de secagem.

O depósito considerado nesse trabalho como depósito novo (DN) constitui um leito de secagem construído de acordo com as exigências legais, impermeabilizados e com sistema de drenagem, onde os resíduos são armazenados temporariamente (Figura 1D). Esses tanques apresentam dimensões variadas, a depender da produtividade da empresa e do volume de resíduos gerados. Os resíduos permanecem nesse local para secagem ao ar livre, sendo, posteriormente, retirados e encaminhados aos aterros definitivos gerenciados por consórcios e associações de empresas.
É importante destacar que as propriedades de alta porosidade e baixa permeabilidade dos resíduos solicitam manutenção cuidadosa do material no leito de secagem. O revolvimento constante é fundamental para se acelerar o processo de secagem, mesmo com o sistema de drenagem devidamente instalado.

O depósito de resíduos de idade considerada intermediária (DI) está localizado em uma encosta (Figura 1E), com declividade em torno de 20 a $30^{\circ} \mathrm{e}$ distante dos canais de drenagem natural. É um depósito não protegido, construído cerca de 5 anos, sem as normas que, atualmente, regulam a disposição dos resíduos. O local não é mais utilizado para descarte, pois a empresa passou a utilizar leito de secagem conforme as exigências legais.

O depósito aqui considerado como antigo (DA) está situado em um vale correspondente a uma planície aluvionar próxima a um canal de drenagem (Figura 1F). O depósito foi desativado cerca de 20 anos e, atualmente, é ocupado por vegetação natural (pasto sujo), situando-se ao lado de uma área de lazer.

Os resíduos dos depósitos foram
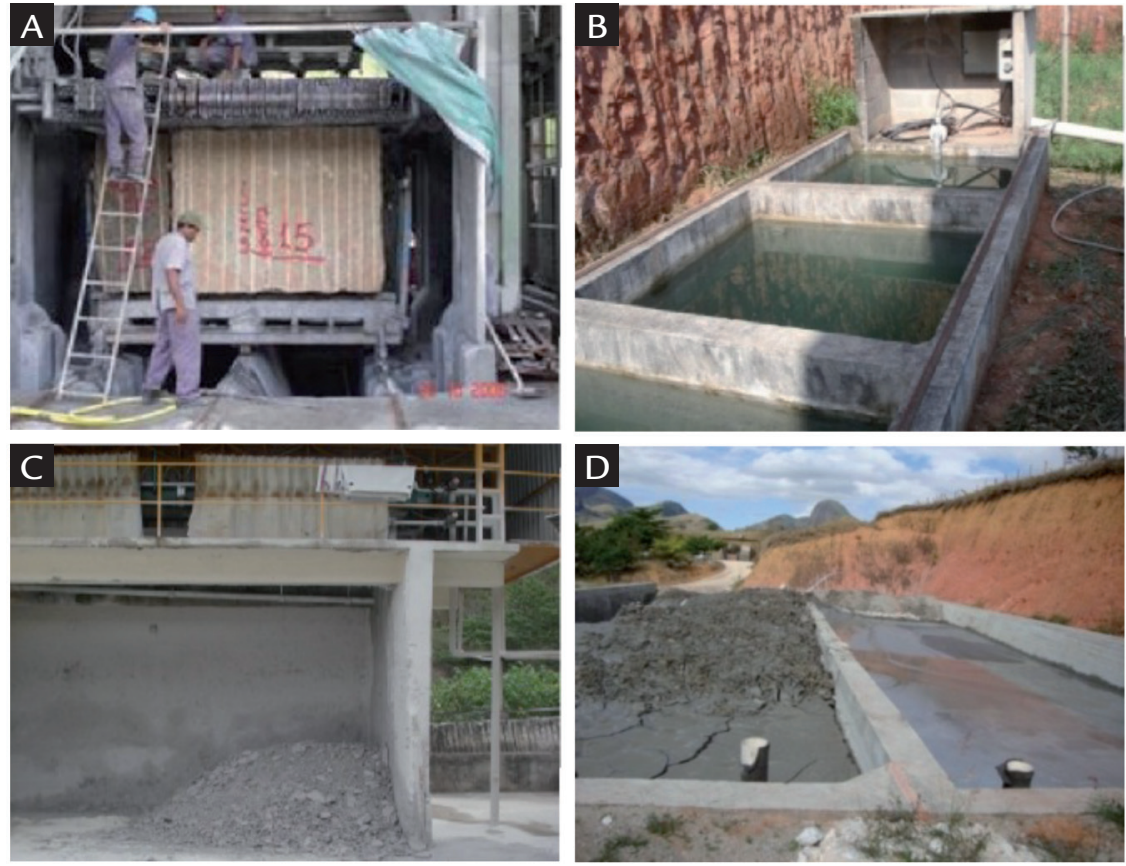

(A) Durante a serragem do bloco em tear convencional.

(B) No tanque de decantação dos resíduos do polimento.

(C) Na saída do filtro-prensa.

(d) Em tanque de secagem de resíduos, que constitui um depósito novo.

(E) Em um depósito de idade intermediária, situado em encosta.

(F) Em um depósito antigo, situado em planície aluvionar.

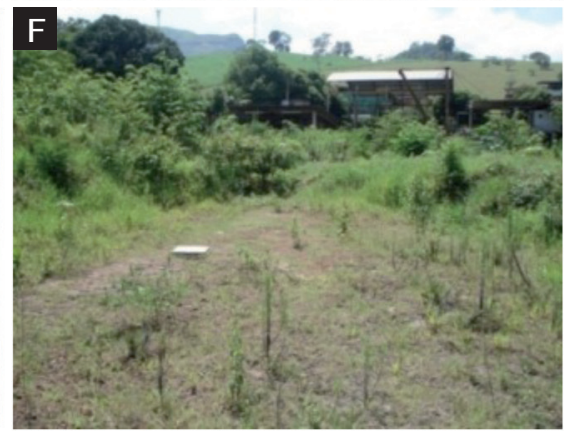


coletados por sondagem a trado, retirando-se amostras a cada metro de profundidade. O depósito antigo foi amostrado até os 3 metros, por ser ele o mais profundo dos depósitos estudados.

Os materiais foram acondicionados em potes de polietileno de boca larga e tampa de rosca, que foram hermeticamente fechados e vedados com parafilme. A vedação é importante, não só para evitar vazamentos durante o transporte, mas, também, para evitar variação do
pH e perda de umidade. A boca larga dos potes facilita a retirada das amostras. Todas as amostras foram mantidas sob refrigeração em caixas de isopor com gelo e levadas, imediatamente, ao laboratório para realização dos ensaios.

A determinação do $\mathrm{pH}$ foi feita em triplicatas e em conformidade com o método da NBR 10.004 (ABNT, 2004a), enquanto a umidade foi obtida de acordo com a NBR 10.006 (ABNT, 2004b). É importante citar que a medida do $\mathrm{pH}$ deve ser feita o mais breve possível, de preferência no local da coleta e no líquido homogeneizado, isto é, a leitura deve ser feita antes da sedimentação das partículas, pois, dessa forma, evitam-se alterações devido à reação com o $\mathrm{CO}_{2}$ atmosférico.

$\mathrm{O}$ tratamento estatístico dos dados foi feito com o programa "R" (R DEVELOPMENT CORE TEAM, 2011), realizando-se análise de variância (ANOVA) e o teste de Tukey com nível de $5 \%$ de probabilidade.

\section{Resultados e discussão}

A Tabela 1 mostra os valores médios de $\mathrm{pH}$ e a umidade dos resíduos es- tudados e sua comparação pelo teste de Tukey em nível de $5 \%$ de probabilidade.

\begin{tabular}{c|c|c|c|c|c|c|c|c|c|c}
\hline Amostra & TE & PO & FP & DN-1 & DN-2 & DI-1 & DI-2 & DA-1 & DA-2 & DA-3 \\
\hline $\mathbf{p H}$ & $11,22^{\mathrm{a}}$ & $9,05^{\mathrm{b}}$ & $9,97^{\mathrm{c}}$ & $9,54^{\mathrm{d}}$ & $9,62^{\mathrm{cd}}$ & $9,09^{\mathrm{b}}$ & $9,18^{\mathrm{b}}$ & $9,13^{\mathrm{b}}$ & $8,68^{\mathrm{e}}$ & $8,48^{\mathrm{e}}$ \\
\hline Umidade (\%) & $39,88^{\mathrm{ad}}$ & $47,63^{\mathrm{b}}$ & $24,55^{\mathrm{c}}$ & $35,50^{\mathrm{de}}$ & $32,47^{\mathrm{ef}}$ & $23,69^{\mathrm{c}}$ & $21,92^{\mathrm{c}}$ & $24,50^{\mathrm{c}}$ & $27,54^{\mathrm{cf}}$ & $44,31^{\mathrm{ab}}$ \\
\hline
\end{tabular}

OBS: Letras iguais nas linhas indicam que os valores não diferem entre si no teste de Tukey em nível de 5\% de significância.

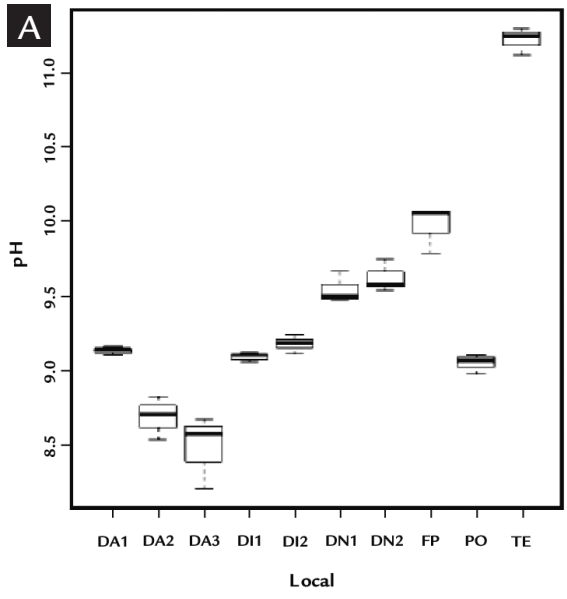

$\mathrm{O} \mathrm{pH}$ mais elevado foi medido no resíduo do tear (TE), mas o valor encontrado $(11,22)$ não o classifica como perigoso de acordo com os critérios da NBR 10.004 (ABNT, 2004a). Os menores valores $(8,68$ e 8,48$)$ foram obtidos nos resíduos do depósito antigo coletados em 2 e 3 metros de profundidade (DA-2 e DA3), os quais não apresentaram diferença

Existem algumas discussões entre os profissionais do setor quanto à necessidade do uso do filtro-prensa para

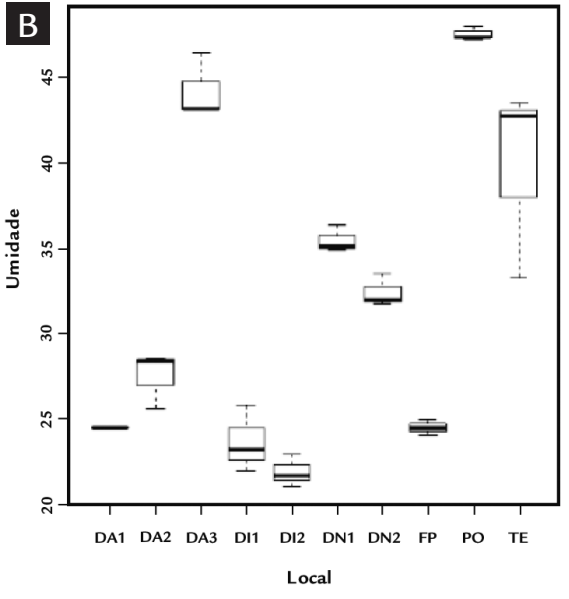

significativa entre si. A retirada de umidade pelo filtro-prensa contribuiu com a diminuição do $\mathrm{pH}$, cujos valores ficaram no mesmo nível do resíduo depositado em leito de secagem (DN-1 e DN-2). Os resíduos do depósito de idade intermediária (DI-1 e DI-2), bem como o do dedade (DA-1), não apresentaram diferença

$$
\begin{gathered}
\mathrm{CO}_{2}+\mathrm{H}_{2} \mathrm{O} \rightarrow\left\langle\mathrm{H}_{2} \mathrm{CO}_{3}\right\rangle \\
\mathrm{H}_{2} \mathrm{CO}_{3}+\mathrm{OH}^{-1} \rightarrow \mathrm{H}_{2} \mathrm{O}+\mathrm{HCO}_{3}^{-1} \\
\mathrm{HCO}_{3}^{-}+\mathrm{OH}^{-1} \rightarrow \mathrm{H}_{2} \mathrm{O}+\mathrm{CO}_{3}^{-2}
\end{gathered}
$$

redução do pH e da umidade em detrimento do leito de secagem, cujo custo é considerado mais acessível para as pósito antigo, em 1 metro de profundi-
A Figura 2 apresenta os valores em gráficos para melhor visualização.

Tabela 1

Valores de $\mathrm{pH}$ e umidade dos resíduos finos de beneficiamento de rochas ornamentais.

Figura 2

Valores de $\mathrm{pH}(\mathrm{A})$ e umidade (B) dos resíduos gerados no parque de beneficiamento e nos depósitos de diferentes idades ( $T E=$ resíduo do tear; $\mathrm{PO}=$ resíduo da politriz; $\mathrm{FP}=$ resíduo do "filtro-prensa; DN = depósito novo; $\mathrm{DI}=$ depósito de idade intermediária; $\mathrm{DA}=$ depósito antigo.

OBS.: os números após as letras indicam a profundidade de coleta.

significativa entre si e todos eles ficaram iguais ao resíduo da politriz (PO).

Comparando-se o pH nos depósitos de diferentes idades, é notória a tendência de diminuição deste parâmetro com o tempo. A neutralização se deve a um processo natural, que ocorre pela difusão de $\mathrm{CO}_{2}$ atmosférico, conforme a reação:

empresas de pequeno porte. Os dados mostram que o filtro-prensa (FP) foi eficaz na redução $\mathrm{pH}$, mas os valores fi- 
caram muito próximos daqueles observados no depósito novo, que constitui um leito de secagem ao ar livre (DN-1 e DN-2). Obviamente é necessário que os tanques sejam construídos de acordo com as normas ambientais e que o material seja revolvido periodicamente para colocar as camadas subsuperficiais em contato com o ar atmosférico.

Com relação à umidade, obtevese o maior valor $(47,63 \%)$ no resíduo gerado durante o polimento (PO). É possível que o teor de umidade seja ainda superior ao valor medido, pois a sedimentação das partículas é muito rápida e, dependendo da forma de coleta, pode-se amostrar uma porção com teor de umidade menor do que o real.

O uso do filtro-prensa reduziu a

\section{Conclusões}

$\mathrm{O} \mathrm{pH}$ dos resíduos gerados, nas diferentes etapas de beneficiamento e depositados em sítios de diferentes idades, não os classifica como perigosos. Ao serem gerados, o $\mathrm{pH}$ desses materiais fica em torno de 11 e, com até dois meses de armazenamento em leito de secagem, cai para 9,5. Esse valor se mantém e decai em depósitos mais antigos, sendo de, aproximadamente, 8,5 o menor valor observado.

Após 3 meses de armazenamento

\section{Agradecimentos}

Os autores agradecem ao Conselho Nacional de Desenvolvimento Científico e Tecnológico - CNPq (processo

\section{Referências bibliográficas}

umidade do resíduo a 24,55\% (FP), atendendo às exigências legais, que determinam que, para ser transportado, o teor máximo de umidade deverá ser de $30 \%$. A secagem do resíduo no depósito novo (DN) reduziu o teor de umidade a 35,50\% (DN-1) e 32,47\% (DN-2), valores próximos do exigido pela norma. O tempo de armazenagem, nesse depósito, foi de, aproximadamente, 3 meses antes da coleta. É possível que a construção de leitos mais amplos e mais rasos acelere a secagem do material, o que tornaria o leito de secagem ao ar livre uma boa alternativa para pequenas e médias empresas. Porém é importante que a impermeabilização e o sistema de drenagem, nesses leitos, sejam feitos de forma adequada e o revolvimento do material deve ser cons- tante. Períodos chuvosos, certamente, aumentarão o tempo de secagem.

O depósito DI, em todas as profundidades amostradas (DI-1 e DI-2), e o DA, em 1 e 2 metros de profundidade (DA-1 e DA-2), apresentaram valores de umidade iguais ao FP. Porém a umidade do DA, em 3 metros de profundidade (DA-3), não apresentou diferença significativa com o resíduo TE e PO, os quais apresentam os maiores valores observados. Portanto, no DA, mesmo após 20 anos, não houve redução da umidade nos níveis mais profundos, o que pode ser explicado pela sua localização topográfica, situada em uma planície aluvionar, onde o nível da água subterrânea é raso o suficiente para manter ou até aumentar o teor de umidade do material. em leito de secagem (DN), o resíduo passa a apresentar teor de umidade próximo ao exigido pelo órgão ambiental capixaba (IEMA). É possível que a disposição em depósitos protegidos, bem drenados e com manutenção adequada, reduza a umidade dos resíduos a menos de 30\% em menos de 3 meses, sendo importante ressaltar que, em períodos chuvosos, esse tempo pode ser estendido.

A umidade dos resíduos de depósitos antigos é influenciada por sua loca- lização topográfica. O depósito antigo (DA) mostrou que, mesmo depois de 20 anos, a taxa de umidade continua elevada por estar situado em planície aluvionar. É importante, portanto, observar as condições em que o depósito está inserido. Declividade, vegetação, características do solo e posição topográfica (topo, vertente, vale) são fatores que devem ser levados em consideração para a disposição destes materiais e para o estudo dos passivos ambientais.

42402794/08) pelo apoio financeiro.
571780/2008-3 e processo 481013/2008-

3) e à Fundação de Amparo à Pesquisa do Espírito Santo - FAPES (processo

\section{4/08) pelo apoio financeiro.}

ASSOCIAÇÃO BRASILEIRA DE NORMAS TÉCNICAS - ABNT. Resíduos sólidos: classificação: 10004. Rio de Janeiro: ABNT, 2004a. 71p.

ASSOCIAÇÃO BRASILEIRA DE NORMAS TÉCNICAS - ABNT. Procedimento para obtenção de extrato solubilizado de resíduos sólidos: 10006. Rio de Janeiro: ABNT, 2004b.3p.

CALMON, J. L., SILVA, S. A. C. Mármore e granito no Espírito Santo: problemas ambientais e soluções. In: DOMINGUES, A. F., BOSON, P. H. G., ALÍPAZ, S. A gestão de recursos hídricos e a mineração. Brasília: Agência Nacional de Águas - ANA, Instituto Brasileiro de Mineração - IBRAM, 2006. p. 199231. Disponível em: <http://www.ana.gov.br/AcoesAdministrativas/CDOC/ CatalogoPublicacoes_2006.asp>. Acesso em: 20 abr. 2011.

FREITAS, J.J.G., RAYMUNDO, V., JESUS, H.C. A importância do monitoramento do $\mathrm{pH}$ em resíduos industriais de beneficiamento de minerais não-metálicos. Cerâmica Industrial, v.14, n.2, p. 1-6, 2009.

INSTITUTO ESTADUAL DE MEIO AMBIENTE E RECURSOS HIDRICOS - IEMA. Instrução a Normativa n. 012 de 03 de dezembro de 2007. Vitória: SEAMA/IEMA, 2007. Disponível em: <http://www.meioambiente.es.gov.br/ default.asp>. Acesso em 26 mai. 2011. 
PEREIRA, F.R. Valorização de resíduos industriais como fonte alternativa mineral: composições cerâmicas e cimentícias. Aveiro, Portugal: Programa de PósGraduação em Ciência e Engenharia de Materiais, Universidade de Aveiro, 2006. (Tese de Doutorado).

R DEVELOPMENT CORE TEAM. R: A language and environment for statistical computing. Vienna: R Foundation for Statistical Computing, 2011. Disponível em <http://www.R-project.org/> Acesso em: 10 jun. 2011.

Artigo recebido em 15 de junho de 2011. Aprovado em 13 de março de 2013. 